\title{
LA IMPLEMENTACIÓN DEL PRINCIPIO DE CIUDADANÍA UNIVERSAL EN LA CONSTITUCIÓN DE ECUADOR DE 2008*
}

\section{IMPLEMENTATION OF THE PRINCIPLE OF UNIVERSAL CITIZENSHIP IN THE CONSTITUTION OF ECUADOR OF 2008}

\author{
Germán Daniel Rodríguez Agudelo* \\ Julián Antonio Navarro Hoyos* \\ Fundación Universitaria Los Libertadores \\ Fecha de entrega: 15.03.2014 \\ Fecha de evaluación: 01.04.2014 \\ Fecha de aprobación: 20.04.2014
}

\section{RESUMEN}

El presente trabajo plantea una reflexión en torno al proceso teórico y político de institucionalización del principio de la Ciudadanía Universal en la Constitución de Ecuador 2008. Para lograr ese propósito, se abordan cuatro aristas: la primera, está constituida por una aproximación al aspecto teórico de la ciudadanía; la segunda, explora el nuevo constitucionalismo latinoamericano como posible marco de comprensión de esta institución y las circunstancias regionales que rodearon la constitución de 2008; el tercer apartado describe las circunstancias internas ecuatorianas que propiciaron la adopción de este principio; y finalmente, se recapitula la experiencia ecuatoriana y las disposiciones constitucionales que formalizaron su inclusión.

\footnotetext{
*Artículo de reflexión producido en el marco del proyecto de investigación "Ciudadanía Universal: conceptos fundamentales y estudio del caso", adelantado por el Grupo de investigación en Estudios Internacionales de la Facultad de Derecho, Ciencias Políticas y Relaciones Internacionales de la Fundación Universitaria Los Libertadores e inscrito en la línea de investigación Derecho y Globalización de la misma institución . Bogotá D.C. (Colombia). Periodo de financiación (Enero- Diciembre de 2012).

*Máster oficial en Modelos y Áreas de investigación en Ciencias Sociales, Universidad de País Vasco. Sociólogo Universidad Nacional de Colombia. Abogado Universidad Pedagógica y Tecnológica de Colombia. Docente investigador de la Facultad de Derecho, Ciencias Políticas y Relaciones Internacionales de la Fundación Universitaria Los Libertadores. Bogotá D.C. Correo de contacto: gdrodrigueza@unal.edu.co

* Máster en Comunidades Europeas y Unión Europea del Real Instituto de Estudios Europeos de Zaragoza España, Becario de la Fundación Carolina 2008-2009. Abogado egresado de la Fundación Universitaria Los Libertadores. Co investigador del Grupo de Investigación en Estudios Internacionales de la Facultad de Derecho de la misma Institución. Correo de contacto: navarrojulianinter@gmail.com
}

REVISTA VIA INVENIENDI ET IUDICANDI, VOL. 8, No. 2

UNIVERSIDAD SANTO TOMÁS, BOGOTÁ

ISSN 1909-0528 


\section{PALABRAS CLAVE}

Ciudadanía universal, hipergüeto, nuevo constitucionalismo, Constitución de Ecuador 2008.

\section{ABSTRACT}

This paper presents a reflection around the theoretical and political process of the institutionalization of the principle of Universal Citizenship in the Constitution of Ecuador of 2008. To achieve this goal, the work addresses four points. The first one consists of a theoretical approach to the issue of citizenship, the second one explores the new Latin American constitutionalism as a possible framework for understanding this institution and the regional circumstances surrounding the 2008 constitution; the third section describes the internal circumstances of Ecuador that led to the adoption of this principle; and finally, it recapitulates the Ecuadorian experience and constitutional provisions that formalized its inclusion.

\section{KEYWORDS}

Universal citizenship, hyper-ghetto, new constitutionalism, Constitution of Ecuador 2008.

\section{Introducción}

La Ciudadanía Universal se constituye como el reconocimiento al ejercicio de los derechos de los migrantes en el contexto de la globalización; dicho principio es producto de los propósitos de movimientos de migrantes periféricos en Europa quienes, por bastantes años, han solicitado el reconocimiento de derechos; sin embargo, en América Latina este tema no parecía estar en la agenda política, de allí la importancia de abordar su estudio, puesto que la Constitución de Ecuador de 2008 adoptó el principio de Ciudadanía Universal convirtiéndose en la primera nación del mundo en consagrar dicho principio, asumiendo así una postura vanguardista en el tema de la ciudadanía que plantea numerosos interrogantes desde el campo teórico. 
La adopción del principio de Ciudadanía Universal se inscribe como una realidad jurídica que surge de las corrientes del "Nuevo Derecho", línea teórica que, entre otras cosas, pretende explorar críticamente la disciplina, desde planteamientos que cuestionan la vigencia de postulados tradicionales del Estado-nación frente al ámbito regulatorio. En este artículo, la consagración de la Ciudadanía Universal se plantea como una salida ante los retos que traza la globalización frente a la ciudadanía, por cuanto se hace necesario y evidente el reconocimiento de derechos de los ciudadanos globales.

Este escrito plantea una reflexión en torno a la consagración del principio de Ciudadanía Universal en la república de Ecuador; para ello, se intenta responder a la pregunta ¿cómo surgió la implementación del principio de Ciudadanía Universal en la Constitución de Ecuador de 2008? Lo que supone, en primer lugar, caracterizar la dimensión teórica de la ciudadanía y conceptual de Ciudadanía Universal; en segundo lugar, contextualizar el surgimiento de la institución a partir del nuevo constitucionalismo latinoamericano; en tercer lugar, identificar las causas internas ecuatorianas que llevaron a la adopción de dicho principio en la Constitución de 2008 y, en cuarto lugar, presentar los artículos de la Constitución ecuatoriana de 2008 relacionados con la movilidad humana, en especial, con el principio de la Ciudadanía Universal, para, posteriormente, presentar unas conclusiones.

De acuerdo con la naturaleza del problema y los objetivos, se pretende abordar el tema a partir de una investigación de tipo documental que parte de un diseño metodológico no experimental y constituye una investigación descriptiva, toda vez que se pretende caracterizar la realidad jurídica de la Ciudadanía universal y los detalles de su primer ejercicio de consagración constitucional. El estudio es cualitativo, pues se funda sobre el análisis de fuentes documentales y centra su atención, fundamentalmente, en el estado actual de la discusión jurídica y política. 
El tema resulta oportuno, por cuanto trata una de las tensiones más importantes que ha enfrentado el derecho tradicional a nivel global durante las últimas décadas. Además de las aristas estrictamente académicas, se trata de un tema de relevancia política fundamental, pues cuestiona la estructura del sistema-mundo colonial/moderno desde el referente jurídico-político de la ciudadanía. Asimismo, tiene una obvia relevancia a nivel nacional, en tanto que Colombia es un país emisor de migración precaria, cuya población en situación irregular se ve impedida para ejercer la ciudadanía en diferentes países del mundo, así como de acudir a cualquier mecanismo de exigibilidad en materia de derechos humanos; de igual forma, la adopción del principio de la Ciudadanía Universal por parte del Ecuador ha propiciado un aumento notorio de la diáspora colombiana en dicho país.

En ese orden de ideas, este artículo se organiza en cuatro secciones; la primera, plantea el aspecto teórico, donde se exploran diferentes acercamientos al tema para luego profundizar en una reflexión a propósito de la teoría del Hipergüeto, planteada por Wacquant (2007) y Bauman (2002); la segunda parte examina el contexto regional, especialmente en el nuevo constitucionalismo latinoamericano como posible marco interpretativo del proceso constituyente de 2008 en Ecuador; la tercera sección se enfoca en los factores que al interior de Ecuador influyeron en la adopción del principio de Ciudadanía Universal; finalmente, en la cuarta sección se detallan los artículos constitucionales relacionados con la implementación del principio a nivel constitucional, para terminar con unas consideración finales.

\section{Aproximación teórica al concepto de ciudadanía}

El concepto de ciudadanía responde a un proceso en constante evolución acorde al modelo de Estado instaurado al interior de los distintos países del mundo, cuyo rasgo distintivo es la integración de personas a un grupo a partir de postulados tanto sociales, como políticos y jurídicos. La ciudadanía se encuentra ligada en la historia a la 
conformación del Estado, puesto que es notorio su avance en la cultura griega, romana, en la época del Cristianismo, en la edad media, el Renacimiento, la modernidad y en la época contemporánea (Horrach Mirales, 2009). No obstante a ello, la noción de ciudadanía se relaciona con la modernidad y la conformación del Estado-nación, la consolidación de la participación democrática y el desarrollo industrial, económico y cultural de las sociedades.

Por tanto, se hace necesaria una precisión preliminar, pues la ciudadanía, como forma organizativa y de reconocimiento al individuo dentro de una sociedad, no es un concepto nuevo, sino que ha estado presente a lo largo de la historia humana. Ese concepto ligado a la historia del hombre, en el contexto de la globalización caracterizada por la flexibilización de las fronteras entre Estados, los flujos de migrantes y el constante cambio en los conceptos básicos del Estado-nación de la modernidadse ve trastocado y tendiente a seguir su evolución (Salazar Benitez, 2005); por lo que se llega afirmar que:

Una de las consecuencias de la globalización son los flujos migratorios que dan como resultado el nacimiento de sociedades multiculturales. La ciudadanía, pensada como estatus de pertenencia a un Estado nación, señala la línea de exclusión de los derechos de aquellos que no son considerados ciudadanos (Sobrados León, 2008, p.12).

Entonces, los pilares básicos del Estado-nación característico de la modernidad llevan a un encuentro con el ascendente orden político y económico del mundo actual, lo que, consecuentemente, ha liberado una crisis y la transformación de la noción moderna de ciudadanía (Lavolpe , 2008). 
Para Kymlicka \& Norman (1997) la ciudadanía consiste en asegurarle a cada persona su membrecía dentro de una sociedad, sin distinción de su tendencia ideológica o cualquier otro comportamiento inherente a la humanidad.

Tres son los elementos más relevantes de la ciudadanía; el primero de ellos es la participación, puesto que cada ser humano es miembro activo de la sociedad en la que se encuentra; el segundo son los derechos, ya que todos los seres humanos son sujetos de derechos y obligaciones sin distinción alguna; y como tercer elemento se tiene la pertenencia, correspondiente a la situación del reconocimiento de un status dentro de una sociedad determinada (Aguilera Portales, 2011).

Marshall (1997), desde un punto de vista sociológico, centró su atención en la ciudadanía dándole a esta un carácter multifacético conformada por tres elementos; civil, político y social. Para Marshall la construcción de un concepto de ciudadanía responde a un proceso histórico comprendido por diferentes etapas que le dieron a las personas un reconocimiento al ejercicio de sus derechos y obligaciones en la sociedad, por tanto, los derechos civiles del siglo XVIII responden al reconocimiento de derechos básicos de la persona, como lo son el acceso a la justicia, al buen nombre, el debido proceso, entre otros; los derechos políticos del siglo XIX corresponden al acceso a la participación ciudadana en la sociedad, donde se identifican el derecho a la asociación, al sufragio, la libertad de expresión; por último, lo derechos sociales culminan el proceso histórico de formación de la ciudadanía y en estos se reconoce a las personas la titularidad y ejercicio de derechos que corresponden al entorno en que se desenvuelven los seres humanos.

Emanuel Kant planteó en siglo XVIII el tema de la ciudadanía mundial como un derecho basado en la hospitalidad, según el cual, un extranjero no podría ser tratado con hostilidad por el solo hecho de llegar a un territorio ajeno. 


\section{El derecho a presentarse en una sociedad se funda en la común}

posesión de la superficie de la tierra; los hombres no pueden diseminarse hasta el infinito por el globo, cuya superficie es limitada, $y$, por lo tanto, deben tolerar mutuamente su presencia, ya que originariamente nadie tiene mejor derecho que otro a estar en determinado lugar del planeta (Kant, 2003, p. 11).

El contexto de estos planteamientos tiene que ver con varias cosas, entre ellas, colonialismo, el racionalismo, el surgimiento de la modernidad y, por supuesto, el nacimiento del idealismo alemán, dentro del cual se supondría que existe un espíritu de la historia que conduce los designios humanos para mejor. Hacia 1920 Hans Kelsen retoma algunos de esos planteamientos (Kelsen, 1920) y los expone con una mayor complejidad, dando apertura a proponer una forma de globalismo jurídico en pleno siglo XX. Es Danilo Zolo (2005) quien, desde su postura crítica, reconfigura el legado kantiano que reposa en la propuesta de Kelsen frente a la extrapolación de la jerarquía piramidal del derecho nacional hacia otra más compleja en la cual los derechos nacionales confluyen sistemáticamente en uno internacional. La crítica pone de presente (Zolo, 2005) que la pretensión de un monismo jurídico internacional es posible sólo presuponiendo una razón universal objetiva dentro de la cual vuelve a aparecer el espíritu universal, que nunca se ha liberado de su matriz eurocéntrica ni colonial.

Ahora bien, en el contexto de la globalización del siglo XXI el mundo asiste a un fenómeno donde la movilidad ha dejado de ser algo ocasional para convertirse en un rasgo constante en todos los conglomerados, donde los flujos migratorios han experimentado una aceleración sin precedentes en la historia; por tanto, se hace necesario "reconocer a los migrantes como sujetos de derechos que comienzan a emprender la gran marcha mundial del pleno ejercicio de su ciudadanía” (Muñoz, 2009), puesto que: 
los migrantes están cambiando, de hecho, la forma de pensar y vivir la democracia y la cultura, son constructores de nueva ciudadanía, primero bi y después plurinacional, finalmente universal, basada en una creciente pluri- identidad; portadores de las nuevas realidades y exigencias; agentes de desarrollo y enriquecimiento multidimensional (Jiménez, 2010, p.7).

En suma, se afirma que la ciudadanía en la actualidad ha sido cuestionada por nuevos retos como, por ejemplo, la necesidad de plantear puntos de vista que no se hallen suscritos al marco nacional; por lo que las disposiciones jurídicas de carácter internacional han servido para configurar los muros del hipergüeto, entendida ésta como una institución organizadora de las relaciones globales; y en ese sentido se ha hablado de ciudadanía postnacional, cosmopolita, transnacional, global y, por supuesto, universal.

Dentro de las diferentes miradas teóricas relacionadas con la ciudadanía universal, sobresale la propuesta teórica del "hipergüeto" de Löic Wacquant (2007), en la cual se plantean estas zonas de exclusión o "zonas de no derecho" como mecanismos de "relegación socio espacial y de cerrazón excluyentes, que se han cristalizado en la ciudad posfordista como efecto del desarrollo desigual de las economías capitalistas y de la desarticulación del Estado de bienestar" (Wacquant, 2007, p. 15). Una de las preceptivas que plantea este autor consiste en que el hipergüeto se ha institucionalizado como una conjugación de mecanismos de control etnoracial fundada en la historia y materializada en la geografía de la ciudad. Pues bien, la caracterización de ese régimen de relegación que el autor consolida sobre una investigación comparativa entre los güetos en Chicago y las banlieues parisinas es utilizada por Zygmunth Bauman (2005), para explicar diversos aspectos relacionados con la migración, entre ellos la ciudadanía, donde realiza, en principio, una extrapolación de tal modelo, llevándolo de la configuración urbana al entorno global con bastante éxito.

REVISTA VIA INVENIENDI ET IUDICANDI, VOL. 8, No. 2 
Lo anterior nos introduce al problema de cómo se producen los güetos globales y cómo es la dinámica que aleja las nuevas periferias o "vertederos de residuos humanos" (Bauman, 2002, p.79) de los centros de poder. Sin dejar de lado que la construcción que tal muro, materializado en ocasiones en las visas generadoras de estatutos de migrantes legales, implica también la segregación del poder de decisión, control y de enunciación, la construcción del sujeto de la periferia, y del sujeto que está al otro lado del muro del güeto.

Al respecto, la disciplina del derecho tiene bastante que decir por el papel que éste juega en la institucionalización de los parámetros de la otredad a partir de los límites que señalan quién y por qué tiene derecho a pertenecer a una sociedad (De Lucas, 2009 , p. 215). Particularmente, este derecho no se refiere a una sociedad en abstracto, sino a habitar en los centros o en las semiperiferias económicas donde existan condiciones materiales mínimas para el desenvolvimiento de una vida digna. En otras palabras, se trata del conflicto por permanecer "adentro" de una frontera que cada día se reduce y se complejiza más, aumentando las masas de personas superfluas para la economía postindustrial.

Por otra parte, la migración suele estudiarse con el mismo prisma, pues no existe barrera que le deje inmune de las influencias que la política ha ejercido tanto en el discurso mediático como en las disposiciones legales donde aparecen representaciones del migrante basadas en una deriva geopolítica, en la cual un meridiano separa el "nosotros" de un imperio aglutinante, de los "otros" ubicados en el lado externo excluido, pobre y salvaje "un amasijo de mundos en declive, de residuos de mundos descompuestos a los que habilidosamente se les hace pasar por algo unitario mediante la uniformización latente en el término general de "tercer mundo", y otras veces se disuelve discursivamente borrando las diferencias entre inmigración y "terrorismo internacional" (Duque, 2009, p.263). Uno de los elementos decisivos en este marco es 
la centralidad del razonamiento binario moderno que señala un adentro y un afuera con sujetos esencializados para analizar unos acontecimientos que naturalmente son más complejos.

En la actualidad, tales razonamientos binarios parecen reproducirse como un mecanismo de defensa ante la inseguridad y transitoriedad que <corroe> las instituciones tradicionales de la vida social. De este modo, la dificultad para administrar las economías nacionales en medio de fenómenos globales, como la crisis del capital especulativo, propicia el hecho de que los poderes estatales, impotentes para contener la incertidumbre, decidan reorientar la animosidad popular hacia objetos al alcance, "desplazarla de los objetos respecto de los cuales nada pueden hacer, a aquellos de los que pueden alardear al menos de que pueden manejar y controlar" (Bauman, 2002, p.88). En resumen, resulta útil para la conservación de algunas hegemonías el administrar la migración como un problema cultural y social para las sociedades de destino. Lo contrario sería tratar el asunto como la consecuencia lógica de la asimetría del sistema-mundo en cuya producción todos hemos participado, eso implicaría afrontar la incertidumbre de la política global, pero también las corresponsabilidades consecuentes.

En todo caso, es necesaria una distinción fundamental: la ciudadanía ha hecho parte de los mecanismos de cerramiento de los flujos migratorios. Y la Ciudadanía Universal se presenta como una potencial oposición a ese esquema. Por supuesto que no se trata de replicar el globalismo productor del hipergüeto, sino de apropiar estratégicamente una institución que podría servir para generar rupturas en los mecanismos de segregación global. En otras palabras, se trata de plantear una herramienta del "globalismo desde abajo" (Fox, 2005, p.194).

\section{El nuevo constitucionalismo latinoamericano: un camino hacia la ciudadanía universal}

REVISTA VIA INVENIENDI ET IUDICANDI, VOL. 8, No. 2

UNIVERSIDAD SANTO TOMÁS, BOGOTÁ

ISSN 1909-0528 
Desde el inicio de la década de 1990 en los países de América Latina se presenta una serie de nuevos procesos constitucionales; a partir del inconformismo colectivo presente al interior de los Estados por la inequidad social, la desigualdad política y las marcadas brechas económicas que afectaban a los pueblos de la región. Por ello, surge el nuevo constitucionalismo latinoamericano como un fenómeno convocado por los movimientos sociales alternativos en busca de generar mecanismos de cambio a nivel institucional y de reconocimiento de derechos fundamentales.

Los nuevos procesos constituyentes en América Latina, y en especial América del Sur, se presentan en dos fases. La primera de ellas inicia con la expedición de la Constitución Política de Colombia de 1991, Argentina 1994, Ecuador 1998 -derogaday Venezuela 1999. La segunda de ellas se identifica con la promulgación de la Constitución de la República del Ecuador de 2008 y la Constitución boliviana de 2009 (Viciano Pastor, Roberto; Martínez Dalmau, Rubén, 2010).

Según Medici (2010), esta nueva tendencia de constituciones - sobre todo la ecuatoriana y la boliviana- parten de un giro descolonial, entendido como "un diagnóstico crítico socialmente extendido sobre la base de la movilización de las mayorías populares" (Medici A, 2009, p. 3), a partir de una conciencia crítica que busca la reformulación de las nuevas cartas constitucionales, llevando al Estado hacia un modelo plurinacional o intercultural que "consiste en una redefinición del concepto de soberanía y en una reasignación de los roles de los ciudadanos dentro de un sistema ligado por la participación" (Pazmiño Freire, 2009, p.29). En ese sentido, se produce la participación de nuevos sujetos en instancias de decisión del Estado, permitiendo, por una parte, un derecho interconectado con la política y los movimientos sociales (García Linera, 2011) y, por otra parte, la vinculación de sectores sociales al Estado que históricamente se mantuvieron excluidos de él, como los pueblos indígenas o los migrantes.

REVISTA VIA INVENIENDI ET IUDICANDI, VOL. 8, No. 2 
Generando así lo que De Sousa denomina el "Estado experimental" (Santos, 2010, p. 110), es decir, un Estado cimentado sobre una constitución transicional, la cual no solo reconoce derechos en un sentido teórico o abstracto sino que va más allá de la literalidad, permitiendo la practicidad de esos mismos derechos a partir de los mecanismo de participación; así las cosas, "el Estado en proceso de refundación asume la transitoriedad de las soluciones no solamente por cuestiones técnicas sino también por cuestiones políticas" (Santos, 2010, p. 111), a partir de dos formas; una, "reflexiva" la cual versa sobre un periodo de transición donde se busca hacer seguimiento a los postulados institucionales estipulados en la constitución y, con posterioridad, mirar su pertinencia; otra, "no reflexiva" que centra su acción sobre la práctica política y jurídica del Estado, donde prevalece la argumentación e interpretación de los derechos.

Según Viciano \& Martínez, cuatro son las características formales del nuevo constitucionalismo latinoamericano: "Su contenido innovador (originalidad), la ya relevante extensión del articulado (amplitud), la capacidad de conjugar elementos técnicamente complejos con un leguaje asequible (complejidad), y el hecho de que se apuesta por la activación del poder constituyente del pueblo ante cualquier cambio constitucional (rigidez)" (2010, p. 14). De igual forma, en el sentido material las nuevas constituciones latinoamericanas se caracterizan por "establecer mecanismos de legitimidad y control sobre el poder constituido a través, en muchos casos, de nuevas formas de participación vinculantes" (2010 p. 20).

Por tanto, las nuevas constituciones latinoamericanas han producido una trasformación institucional a partir de un llamado social, redireccionándose el papel del ciudadano dentro de las premisas democráticas, estipulando nuevos instrumentos y mecanismos en busca de permitir la participación directa de la población de un Estado en la toma de decisiones en relación con los asuntos públicos. Así, estas constituciones permiten la inclusión social en las democracias y contienen un amplio catálogo de derechos 
fundamentales (Carbonell, 2010) que buscan darle prevalencia a los derechos humanos.

\section{Factores que influyeron en la adopción del principio de ciudadanía universal en la constitución del Ecuador}

Una vez reseñadas la incidencias tanto teóricas como regionales en torno a la adopción del principio de Ciudadanía Universal en la Constitución de Ecuador de 2008, se presentan las incidencias directas al interior del Estado ecuatoriano que, de una u otra forma, llevaron a la implementación del principio a favor de los migrantes; así, se identifican dos factores: el primero, endógeno, referente a la crisis institucional ecuatoriana de finales de la década del noventa; y el segundo factor hace alusión al fenómeno de la migración ecuatoriana.

\section{A. Factores endógenos: crisis institucional}

Como se mencionó anteriormente, durante los años noventa se presentó una oleada de nuevas constituciones en América Latina; esta tendencia permeó la mayoría de procesos constituyentes de manera determinante. Ecuador no fue la excepción, la Constitución de 1998 acogió un modelo neoliberal, asumiendo la pretensión de reducir el tamaño del Estado a través de las privatizaciones y la generación de modelos de participación directa que no lograron el cometido de ganar gobernabilidad entre las instancias populares (Ortiz Crespo, 2008, p. 14). Por otra parte, fue visible la debilitación del ejecutivo para incidir en la economía nacional y el correlativo desmonte de la maquinaria estatal que aún quedaba del modelo intervencionista (Quintero, 2008, p.10).

Como consecuencia de lo anterior, tuvo lugar una crisis sin precedentes de la estabilidad institucional que afectó al Ecuador desde 1995, con la emergencia de

REVISTA VIA INVENIENDI ET IUDICANDI, VOL. 8, No. 2 
nuevos actores políticos, entre ellos los indígenas, quienes ingresaron en la arena política buscando reivindicaciones identitarias, históricamente pendientes. Es así como en el año 1997, después de ingentes manifestaciones, es destituido el presidente Abdalá Bucaram. La agitación terminó en una asamblea constituyente que dio como fruto la Constitución de 1998. Se ha criticado que si bien en aquel texto se reconocieron algunos derechos no se afectó la estructura centralista y, por lo tanto, no se generaron condiciones para una participación visible (Ortiz Crespo, 2008).

Pese a que la Constitución generó algunos mecanismos de participación directa no tuvo la capacidad de generar consensos sociales. Tal vez por esta razón en el año 2000 el movimiento indígena lideró un nuevo levantamiento que derrocó al presidente Jamil Mahuad y puso al mando a una junta indígena-militar que, finalmente, entregó la dirección del gobierno al vicepresidente Gustavo Novoa (Ramírez, 2011). Las elecciones de 2002 dieron la victoria al coronel retirado Lucio Gutiérrez, quien tuvo que dimitir en 2005 luego de la denominada "rebelión de los forajidos". La dirección del Estado es asumida entonces por el vicepresidente Alfredo Palacio. Como puede observarse, la tensión política y la inestabilidad institucional era un asunto muy complejo. En estas circunstancias Rafael Correa gana las elecciones para el periodo 2007-2011 como fruto de una coalición entre partidos, especialmente entre Alianza País y el Partido Socialista (Quintero, 2008, p. 8).

Pero la crisis no fue solamente en la estabilidad institucional, pues acaece también una caída sensible en el PIB "Este declinó en -30,1\%, de 19.710 millones de dólares en 1998, pasó a 13.769 millones en 1999. El PIB por habitante se redujo en casi 32\%, al desplomarse de 1.619 a 1.109 dólares" (López \& Acosta, 2003).

La crisis económica generada fue una de las causas de la estampida migratoria (19992000). Se estima que desde entonces ha salido del Ecuador más del $10 \%$ de la 
población y que sólo en España se han ubicado unos 2.5 millones de nacionales de ese país (López \& Acosta, 2003).

Sin duda, estos acontecimientos influyeron tanto en la adopción de una nueva Constitución como del principio de Ciudadanía Universal, ya que se busca, por una parte, terminar con el inconformismo social y, por otra, generar garantías individuales a determinados grupos que históricamente habían quedado excluidos de la participación estatal, entre ellos los migrantes.

\section{B. Factor migratorio}

El otro factor decisivo en la implementación del principio de Ciudadanía Universal en la Constitución ecuatoriana de 2008 fue la emergencia de la migración como actor político. En efecto, desde los años noventa comenzó a presentarse la migración como un elemento importante en diferentes ámbitos. Por una parte, sobresale en el terreno económico a través de las remesas que llegan a constituir un porcentaje importante del PIB ecuatoriano; por otra, se convierte en un competido campo de estudio por parte de las ONG y universidades interesadas en observar el fenómeno de la familia transnacional, sin que se destinara mayor visibilidad a la necesidad de una política pública en la materia.

Si bien, a finales de los noventa la magnitud de la población migrante es muy importante, el periodo de inestabilidad institucional comprendido entre 1997 y 2000 genera un flujo de movilidad que se le ha denominado la estampida migratoria (Ramírez \& Quezada, 2010). En ese momento la movilidad de la población se convierte en un tema ineludible para el gobierno.

Rafael Correa Delgado es elegido en 2006 luego de una coalición que recogió el descontento electoral. Desde su candidatura, Correa planteó la necesidad de tratar más

REVISTA VIA INVENIENDI ET IUDICANDI, VOL. 8, No. 2 
seriamente los temas migratorios y se refirió a los migrantes como la "quinta región". De este nuevo impulso surgieron el Plan de Desarrollo Humano de las Migraciones (20072010), el Plan Nacional del Buen Vivir (2009-2013) y, por supuesto, la iniciativa que terminó en la Constitución Política de 2008. Adicionalmente, se creó la Secretaría Nacional del Migrante (Senami) con sedes en las ciudades donde residen las colonias ecuatorianas más grandes (Madrid, New York, Génova y Caracas) (Ramírez \& Quezada, 2010, p. 215).

La migración es un factor decisivo en la adopción de la Ciudadanía Universal en Ecuador, ya que con este principio se busca conseguir una reciprocidad en el trato a los nacionales ecuatorianos en el extranjero, igual al que reciben los foráneos en el territorio de Ecuador.

\section{La Constitución ecuatoriana de 2008 como impulsota del principio de ciudadanía universal}

A. La Constitución de 2008 y la movilidad humana

La adopción del principio de Ciudadanía Universal en la Constitución de Ecuador de 2008 es un elemento que sintetiza un complejo proceso, en la cual la migración se fue abriendo campo hasta conquistar espacios dentro las políticas públicas, para luego llegar a ser un tema transversal en la Constitución Política.

La Constitución de 2008 es un texto complejo que se encuentra atravesado por diversos planteamientos; de este modo, junto a los planteamientos dogmáticos liberales y a los catálogos de derechos usuales en las constituciones contemporáneas, existen otros elementos innovadores. A nivel filosófico está "El buen vivir o Sumak Kawsay", estructura conceptual que se opone al discurso sobre el desarrollo. 
Con el discurso del desarrollo desde sus visiones modernizadoras en los años 50, hasta sus visiones neoliberales en las últimas décadas del siglo $X X$, se establece una visión del tiempo lineal en que la historia tiene un solo sentido, una sola dirección... Las diversidades fueron consideradas como un obstáculo para el progreso y por consiguiente las élites impulsaron un proceso de homogenización de los sectores subalternos.

Los pueblos indígenas andinos aportan a este debate desde otras epistemologías y cosmovisiones y nos plantean el Sumak Kawsay, la vida plena, que implica amplias relaciones, entre los seres humanos, la naturaleza, la vida comunitaria, los ancestros, el pasado y el futuro (Larrea Maldonado, 2011, p. 60).

En el tema de la migración no es clara la influencia de esta filosofía como sí lo es en el aspecto ambiental con la consagración de los derechos de la naturaleza (Constitución Política del Ecuador, 2008. art. 72). No obstante, para Ramirez (2011, p.65) la filosofía del Sumak Kawsay, precisamente, se halla en la mirada integral de la movilidad al contemplar la reglamentación de las familias transnacionales, la seguridad social, la participación política, el control ciudadano, entre otras. Por otra parte, la Ciudadanía Universal es una manifestación frente a la necesidad de un equilibrio global de los ciudadanos del mundo, en tanto que dentro de la concepción del buen vivir es impensable que unas personas puedan acceder al ejercicio pleno de la ciudadanía y otros no. Es decir, que no podría darse bienestar para unos y para otros no, puesto que se desequilibraría el balance integral.

La Constitución de 2008 tiene 57 artículos que mencionan el tema de la movilidad humana a lo largo de todo su contenido, por eso se afirma que se trata de un tema transversal en el texto superior.

REVISTA VIA INVENIENDI ET IUDICANDI, VOL. 8, No. 2

UNIVERSIDAD SANTO TOMÁS, BOGOTÁ

ISSN 1909-0528 
En el capítulo tercero, denominado "Derechos de las personas y grupos de atención prioritaria", se encuentra, en la sección tercera, el apartado titulado "la movilidad humana", el cual se menciona a continuación por su carácter emblemático:

Art. 40.- Se reconoce a las personas el derecho a migrar. No se identificará ni se considerará a ningún ser humano como ilegal por su condición migratoria. El Estado, a través de las entidades correspondientes, desarrollará entre otras las siguientes acciones para el ejercicio de los derechos de las personas ecuatorianas en el exterior, cualquiera sea su condición migratoria:

1. Ofrecerá asistencia a ellas y a sus familias, ya sea que éstas residan en el exterior o en el país.

2. Ofrecerá atención, servicios de asesoría y protección integral para que puedan ejercer libremente sus derechos.

3. Precautelará sus derechos cuando, por cualquier razón, hayan sido privadas de su libertad en el exterior.

4. Promoverá sus vínculos con el Ecuador, facilitará la reunificación familiar y estimulará el retorno voluntario.

5. Mantendrá la confidencialidad de los datos de carácter personal que se encuentren en los archivos de las instituciones del Ecuador en el exterior. 


\section{Protegerá las familias transnacionales y los derechos de sus} miembros (Constitución Política del Ecuador, 2008, Art. 40).

Sin duda, este artículo muestra la influencia de los migrantes y de su problemática más grave, por la forma como se reconoce el derecho a migrar y por la crítica implícita a la expulsión como medida usual frente a las personas indocumentadas. Entre tanto, en la segunda parte se encuentran unas directrices que, se supone, servirán para orientar y desarrollar iniciativas de política pública en esa área. Pero el aspecto más importante del artículo es reconocer que la acción del Estado no se limita a su territorio, sino que sus deberes se desplazan con sus nacionales. Esta circunstancia se ve más clara en el numeral 6 , en donde se reconoce a la familia transnacional, la cual se constituye cuando uno o más de sus miembros que se encuentran en situación migratoria, frente a lo cual el Estado debe protección tanto al migrante como a cualquier miembro de su familia. Este fenómeno, que comenzó siendo un de interés académico, terminó consolidándose en el reconocimiento de la transnacionalidad de esta institución. En el mismo sentido, los artículos 45 y 69, en su numeral 4 , hacen alusión a dicho estipulado.

Existen otras disposiciones vinculadas con el tema, como el artículo 6 en donde se contempla la doble nacionalidad y el derecho al voto de los nacionales en el exterior (artículos 62 y 63); además, se menciona el derecho al sufragio para los extranjeros que hayan vivido por lo menos cinco años dentro del territorio nacional. En este campo hay una apertura significativa, puesto que se contemplan los mecanismos de participación ciudadana como un derecho que pueden ejercer los nacionales en el exterior (artículos 102 y 104); se establece, del mismo modo, la circunscripción especial extraterritorial.

Adicionalmente, los ecuatorianos en el exterior pueden participar en el "cuarto poder del Estado", al otorgárseles la facultad de ejercer el control ciudadano, para lo cual pueden postularse para ser candidatos, (artículo 207). De la misma forma, se menciona el deber 
del Estado de promover convenios para la regulación de los nacionales indocumentados fuera de su territorio (artículo 329) y la posibilidad de cotizar al sistema de seguridad nacional (artículo 374).

B. La incorporación del principio de Ciudadanía Universal

El título VIII de la Constitución regula las relaciones internacionales, y en el primer capítulo se vislumbran los principios rectores de las mismas; seguidamente, en el artículo 416, N 6, se encuentra la mención al Principio de la Ciudadanía Universal en los siguientes términos:

6. Propugna el principio de ciudadanía universal, la libre movilidad de todos los habitantes del planeta y el progresivo fin de la condición de extranjero como elemento transformador de las relaciones desiguales entre los países, especialmente Norte-Sur (Constitución Política del Ecuador, 2008. Art. 416).

En este punto confluye todo lo dicho en este artículo. Pero ¿qué implica tener la Ciudadanía Universal como un principio rector de las relaciones internacionales? ¿Acaso el principio puede restringirse sólo a la órbita de las relaciones internacionales dejando el espacio nacional intacto? ¿Qué implicaciones tiene para los extranjeros en Ecuador esta disposición? Estas preguntas aún están por responderse. Sin embargo, es pertinente decir que se trata de un principio aplicable a las relaciones internacionales, pues así está planteado en la Constitución ecuatoriana de 2008; es decir, que no se encuentra entre los principios del Estado ni en el preámbulo, lo que tendría otras consecuencias, está únicamente en el título octavo de la Carta.

En ese sentido se puede afirmar con Ramírez \& Quezada (2010, pág. 209) que se trata de una "invitación a la comunidad internacional a que abandonen la discriminación, el racismo y la xenofobia como patrones de relación humana..." Por otra parte, Estévez

REVISTA VIA INVENIENDI ET IUDICANDI, VOL. 8, No. 2

UNIVERSIDAD SANTO TOMÁS, BOGOTÁ

ISSN 1909-0528 
(2008, pág. 25) menciona que del principio en cuestión se desprende una idea de justicia global descolonial, el cual implica la construcción de una epistemología que implique reconocer la dimensión individual y colectiva de los migrantes, pero también las relaciones de poder entre países.

Sea como fuere, se trata de la primera vez que se estatuye un principio de esta naturaleza y, por lo tanto, falta ver cuál será el contenido que se le otorgará en su desarrollo. Si se realiza una interpretación de acuerdo con el conjunto del capítulo debe observarse como un instrumento que debe propugnar por la justicia y la equidad en el tratamiento del tema migratorio; no obstante, es sabido que sus consecuencias internas han sido significativas.

\section{Conclusiones}

El concepto tradicional de ciudadanía se encuentra ligado a la historia de la evolución humana, la conformación del Estado, y se entiende como un reconocimiento a las personas para ejercer derechos y contraer obligaciones en un territorio determinado. En el contexto de la globalización, ese concepto se ve flexibilizado por el alto nivel de flujos migratorios de personas entre Estados que hacen de las personas ciudadanos transestatales, es decir, que no pertenecen a un Estado determinado, sino que las personas se convierten en ciudadanos del mundo, toda vez que ejercen actividades civiles, políticas y sociales en distintos territorios, lo que conduce a la consolidación del concepto de Ciudadanía Universal.

En el aspecto teórico, resulta paradójico cómo puede formularse un globalismo como la Ciudadanía Universal y pretender que se asuma como una propuesta contrahegemónica, cuando las pretensiones universalistas han sido el vehículo epistemológico por excelencia de la colonialidad. No obstante, en el planteamiento concreto que se efectúa con ocasión de la Constitución ecuatoriana de 2008, es

REVISTA VIA INVENIENDI ET IUDICANDI, VOL. 8, No. 2 
evidente el sentido político de ruptura al mirarlo como una especie de universalismo estratégico, a través de cual se busca refutar el monismo universalista kelseniano con sus propios postulados, permeando el discurso tradicional, para generar herramientas de exigibilidad que permitan mitigar la asimetría en la que se encuentran los ciudadanos de los países históricamente empobrecidos dentro o fuera del territorio de su Estadonación.

La Ciudadanía Universal asume la línea del uso alternativo del derecho, que parte de la asunción de que el derecho tiene un uso hegemónico, el cual se utilizaría para reproducir un estado de cosas asimétrico, pero que es posible para el abogado como intelectual orgánico asumirlo como una herramienta para generar fracturas a los postulados tradicionales; en ese sentido, la Ciudadanía Universal es, sin duda, una institución que ya no reside en la utopía, sino en la realidad jurídica al consagrarse en la Constitución de Ecuador de 2008.

Esa implementación surgió de diferentes factores, entre los que se encuentran, por una parte, el contexto constitucional latinoamericano caracterizado por el reconocimiento de derechos a las minorías, donde se consolida el Estado plurinacional o intercultural, que apoya desde un punto de vista práctico teórico la consagración del principio de Ciudadanía Universal; por otra parte, a nivel interno del Ecuador la crisis institucional que afectó a dicho país a finales de la década de 1990 e inicios de 2000, ahondo una crisis económica que, a su vez, produjo un amplio flujo migratorio de personas hacia otras partes del mundo, teniendo como consecuencia que a la población migrante se le identificara como componente importante a la hora de implementar políticas públicas; lo anterior condujo a un proceso de formación del sujeto político migrante desde los logros más tímidos, como pueden ser los intentos de asociación en los países de destino, hasta la inclusión del tema en la Constitución de 2008 y su correlativa exigibilidad. 
Por tanto, al observar la implementación del principio de Ciudadanía Universal en la Constitución ecuatoriana de 2008 , se comprueba que no es un artículo aislado en el texto constitucional sino que está inmersa en toda una institucionalidad conquistada por ese fragmento del poder constituyente, como lo es la población en situación de movilidad y se concreta en las funciones del Estado, en las garantías para la familia transnacional, en la diplomacia participativa, en la seguridad social y en otros ámbitos que hacen pensar en la transformación inevitable del carácter nacional de las instituciones tradicionalmente consignadas en las constituciones latinoamericanas, lo que ciertamente evidencia que la Constitución de 2008 es un texto de vanguardia en este campo.

\section{Referencias}

Aguilera, R. E. (2011). La Ciudadanía ante la globalización: Nuevos modelos de ciudadanía Postnacional y Transcultural. Revista de Derecho UNED(8), 13 - 48.

Bauman, Z. (2002). Vidas desperdiciadas. La modernidad y sus parias. Barcelona: Paidós Ibérica.

Bauman, Z. (2005). La unión desmantelada. En Amor líquido. Acerca de la fragilidad de los vínculos humanos (págs. 155-201). Buenos Aires: Fondo de Cultura Económica.

Carbonell , M. (2010). Desafios del nuevo constitucionalismo en América Latina. Precedente, 207-225.

Constitución Política del Ecuador. (20 de Octubre de 2008). Ministerio de relaciones Exteriores, Comercio e Integración de Ecuador. Recuperado el 30 de Junio de 2012, de http://www.mmrree.gob.ec/ministerio/constituciones/2008.pdf

De Lucas, J. (2009). Discursos sobre lo invisible. En J. (. Borja, Los otros entre nosotros. Alteridad e inmigración. Madrid: Universidad Autónoma de Madrid.

REVISTA VIA INVENIENDI ET IUDICANDI, VOL. 8, No. 2 
Duque, F. (2009). Hombres sin Rostro, tierra en blanco. En J. Borja, Los otros entre nosotros. Alteridad e inmigración (págs. 255-301). Madrid: Universidad Autónoma de Madrid.

Estévez, A. (2008). Migración, globalización y Derechos Humanos. Construyendo la ciudadanía universal. Mexico D.F.: UNAM - CISAN.

Fox, J. (2005). Unpacking "transnational citizenship". Review of political science Vol. 8, $171-201$.

García, Á. (2011). El Estado Plurinacional y la nueva Constitución boliviana. Critica y Emancipación(6), 53-64.

Horrach, J. A. (2009). Sobre el concepto de ciudadanía: historia y modelos. Factótum(6), 1- 22.

Jimenez, R. (2010). Un grito por la ciudadanía universal. Migración y nuevas formas de ciudadanía en el Siglo XXI. América Latina en Movimiento, II(460), 2-5.

Kant, I. (2003). La paz perpetua. Buenos Aires: Biblioteca virtual universal. Disponible en: http://www.biblioteca.org.ar/libros/89929.pdf.

Kymlicka \& Norman (1997). El retorno del Ciudadano. Una revisión de la producción reciente en la teoría de la Ciudadanía. Ágora, núm. 7, 1997, 5-42

Kelsen, H. (1920). Das problem der soveränität und die theorie des völkerrechts. Tubingen. : Mohr. Citado por Zolo, D. (2005) Los señores de la paz. Una crítica al globalismo jurídico. Editorial Dykinson.

Larrea, A. M. (2011). El buen vivir como contrahegemonía en la Constitución Ecuatoriana. Utopía y Praxis Latinoamericana(53), 59 - 70.

Lavolpe , F. (2008). Las nuevas ciudadanias de la globalización. Hologramática, 6(8), 47-65.

Llactacaru. (2012). Llacta! Recuperado el 29 de Junio de 2012, de http://www.llacta.org/organiz/llactacaru/

López, S. \& Acosta, A. (Enero de 2003). Cartillas sobre migración: Plan migración, comunicación $y$ desarrollo. Obtenido de http://www.llacta.org/organiz/llactacaru/docs/migracion03.pdf 
Marshall, T. H. (1997). Ciudadanía y clase social. Revista española de investigaciones sociológicas, 297-344.

Medici, A. (2009). Ocho proposiciones sobre el nuevo constitucionalismo latinoamericano y el giro descolonial: Bolivia y Ecuador.

Medici, A. M. (Octubre de 2010). El nuevo constitucionalismo latinoamericano y el giro descolonial: Bolivia y Ecuador. Revista de Derecho y Ciencias Sociales(3), 3-23.

Muñoz, J. (2009). Derechos Humanos, Migraciones y Ciudadania Universal. Dialogos Migrantes(2), 8 - 20.

Ortiz, S. (2008). Participación ciudadana: la Constitución de 1998 y el nuevo proyecto constitucional. Íconos. Revista de ciencias Sociales(32), 13-17.

Pazmiño, P. (2009). Algunos elementos articuladores del nuevo constitucionalismo latinoamericano. Cuadernos constitucionales de la Cátedra Fadrique Furió Ceriol(67/68), 27- 54.

Quintero, R. (2008). La Constitución del 2008: un análisis político. Quito: Abya - Yala.

Ramírez, J. (2011). Repensando el Estado-nación en clave migratoria: del enfoque de control al enfoque de derechos. Línea Sur, 57-69.

Ramírez, J. \& Quezada, G. (2010). Política migratoria y los avances en movilidad humana en la nueva constitución. En J. Ramíres Gallegos, Con o sin pasaporte: análisis socio-antropológicosobre la migración ecuatoriana (pp. 209-226). Quito: Editorial Instituto de Altos Estudios Nacionales (IAEN).

Salazar, O. (Enero- Marzo de 2005). El derecho a la identidad cultural como elemento hacia una ciudadanía compleja. Revista de Estudios Politicos (nueva epoca)(127), 297-322.

Sobrados, M. (2008). Construir ciudadanía ante el debate de las minorias étnicas. El reto de los medios de comunicación. Comunicación y Ciudadanía(6).

Santos, B. (2010). Refundación del Estado en América Latina. Perspectivas desde una epistemología del Sur. Quito: Abya Yala.

Viciano, R. \& Martinez, R. (6- 10 de Diciembre de 2010). ¿Se puede hablar de un nuevo constitucionalismo latinoamericano como corriente doctrinal sistematizada? VII

REVISTA VIA INVENIENDI ET IUDICANDI, VOL. 8, No. 2 
RODRÍGUEZ A., GERMÁN DANIEL; NAVARRO H., JULIÁN ANTONIO (2013): “IMPLEMENTACIÓN DEL PRINCIPIO DE CIUDADANÍA UNIVERSAL EN LA CONSTITUCIÓN DE ECUADOR DE 2008", VIA INVENIENDI ET IUDICANDI, VOL. 8. No. 2, PP. 53-78

Congreso Mundial de la Asociación Internacional de Derecho Constitucional "Constituciones y Principios". Mexico D.F., Mexico.

Wacquant, L. (2007). Los condenados de la ciudad. Gueto, periferias y Estado. Madrid: Siglo XXI.

Zolo, D. (2005). Los señores de la paz. Una crítica al globalismo jurídico. Madrid: Dykinson. 